Article

\title{
Run Theory and Copula-Based Drought Risk Analysis for Songnen Grassland in Northeastern China
}

\author{
Rina $\mathrm{Wu}^{1}{ }^{1}$, Jiquan Zhang ${ }^{2, * \mathbb{C}}$, Yuhai Bao ${ }^{3, *}$ and Enliang $\mathrm{Guo}^{3}$ \\ 1 School of Geography, Liaoning Normal University, Dalian 116029, China; wurina@lnnu.edu.cn \\ 2 School of Environment, Northeast Normal University, Changchun 130024, China \\ 3 College of Geography, Inner Mongolia Normal University, Hohhot 010022, China; guoel1988@imnu.edu.cn \\ * Correspondence: zhangjq022@nenu.edu.cn (J.Z.); baoyuhai@imnu.edu.cn (Y.B.)
}

Received: 17 September 2019; Accepted: 23 October 2019; Published: 30 October 2019

\begin{abstract}
Droughts are among the more costly natural hazards, and drought risk analysis has become urgent for the proper planning and management of water resources in grassland ecosystems. We chose Songnen grassland as a case study, used a standardized precipitation evapotranspiration index (SPEI) to model drought characteristics, employed run theory to define the drought event, and chose copula functions to construct the joint distribution for drought variables. We applied two kinds of return periods to conduct a drought risk assessment. After evaluating and comparing several distribution functions, drought severity (DS) was best described by the generalized extreme value (GEV) distribution, whereas drought duration (DD) was best fitted by gamma distribution. The root mean square error (RMSE) and Akaike Information Criterion (AIC) goodness-of-fit measures to evaluate their performance, the best-performing copula is Frank copula to model the joint dependence structure for each drought variables. The results of the secondary return periods indicate that a higher risk of droughts occurs in Keshan county, Longjiang county, Qiqiha'er city, Taonan city, and Baicheng city. Furthermore, a relatively lower risk of drought was found in Bei'an city, Mingquan county, Qinggang county, and qian'an county, and also in the Changling county and Shuangliao city. According to the calculation of the secondary return periods, which considered all possible scenarios in our study, we found that the secondary return period may be the best indicator for evaluating grassland ecosystem drought risk management.
\end{abstract}

Keywords: drought risk analysis; the secondary return period; run theory; copula

\section{Introduction}

Droughts are among the most cost hazards of natural disasters due to the fact that their impacts are significant and widespread, affecting many economic sectors and people at any one time. The damage of grassland drought has been a challenging issue in prairies and has been receiving increasing attention from all over the world. China's grassland is located in the Northern and Western regions, where annual precipitation is less than $400 \mathrm{~mm}$ and livestock disasters often occur because of frequent droughts. The extent of the harm is at the head of all kinds of meteorological droughts. The frequency of drought in Inner Mongolia appeared to be up to $65.8 \%$, according to Inner Mongolia drought disaster historical statistics data. The annual average drought disaster areas reach 24.59 million hectares, and drought rate reaches up to $39.47 \%$; further, the average annual mortality rate of livestock is $4.7 \%$ due to drought [1]. The capacity for the prevention and mitigation of drought is relatively low, and farmer's lack of knowledge of prevention and mitigation for disaster, to a certain extent, increased the losses caused by disasters in the prairie area of China. Therefore, the grassland drought monitoring and grassland drought risk analysis have become a very urgent task. It is great significance to protecting grassland ecological security and promoting sustainable socio-economic development in prairie areas. 
At present, there are a number of drought indexes for drought analysis, monitoring, and assessment. These indexes include the Palmer drought severity index (PDSI) [2], based on a soil water balance equation; the standard precipitation index (SPI) [3], which is based on precipitation and provides a measure for water supply; the moisture anomaly index (Z-index) [4], based on the water balance equation; the effective drought index (EDI) [5], based on the water accumulation with the weighting function of time passage; the aggregated drought index (ADI) [6], based on monthly (measured) input data; the composite index (CI) [7], based on potential evapotranspiration accumulating methods; the reconnaissance drought index (RDI ) [8], based both on precipitation and on potential evapotranspiration; the standard precipitation evapotranspiration index (SPEI) [9]; and so on. Each index has its advantages and disadvantages, and different research areas should select appropriate indicators. The SPEI integrates the advantages of PDSI to changes in evaporation demand (caused by temperature fluctuations and trends) with the simplicity of operation and the multi-scale of the SPI. The SPEI is a comparatively new index and is mainly used in detecting, monitoring, and evaluating the results of global warming on extreme climate event (i.e., drought) conditions. Therefore, we have selected the SPEI as the drought analysis indicator for characterizing drought events.

The copula probability distribution function as a correlation analysis and multivariate modeling is suitable for building the joint distribution of marginal distribution, has unique advantages for dealing with non-linear, non-symmetrical data, and is an effective means for the description of the variables' correlation. Since the 21st century, copula functions have been widely used in the finance, meteorology, hydrology, and natural disaster risk research fields. Shiau [10] first used six kinds of Archimedean copula function to link up the marginal distribution of drought duration and drought intensity and then established joint probability distributions to conduct a frequency analysis of meteorological drought events. Song and Singh [11] used five kinds of meta-elliptical copula functions to construct the joint probability of drought duration, interval, and intensity, and compared them with the results of Archimedean copula analysis. In a recent drought study, the copula function was used to build the joint distribution functions of drought duration and drought severity, and then to calculate the joint distribution of drought duration and severity and analysis joint return period [12-14]. There is a strong relationship between drought duration and drought severity, and the univariate analysis of drought frequency does not completely characterize drought events. The bivariate frequency analysis can be used as an effective tool for considering the drought occurrence and connecting the drought characteristics simultaneously. In addition, the joint multivariate models of droughts are hard to create, due to the fact that the drought duration and severity always comply with different distributions. Furthermore, both drought duration and severity play a significant role to drought frequency analysis and management, and it is necessary to calculate a joint return period for drought characteristics. Due to this reason, copulas were applied to connect fitted univariate distributions and then construct a bivariate joint distribution.

There have been numerous studies conducted for drought frequency analysis using copula functions in different parts of the world [15-18]. Therefore, we chose Songnen grassland as a case study, using the standardized precipitation evapotranspiration index (SPEI) to model drought characteristics and employ run theory to define the drought event and explore drought regularity within the study area. The copulas are applied to construct the joint distribution function for the marginal distribution function of drought severity and duration. In addition, the value of variables achieved in a copula function is varied as a curve and we assume that events that have the same return period have the same disaster; the return period of a drought event that is greater than or equal to one return period value has great significance for drought risk analysis. In addition, the proper design and rational use of water resource under drought conditions need the accurate estimation of the return periods for drought events, which are mostly characterized by high severities [19]. Therefore, Salvadori and De Michele [20] defined the secondary return period, which will be conducted in this study for drought risk analysis. 
The remaining sections are designed as follows: First, the descriptions of the study area and data sources are presented. Then, the definition of the copula function and its properties and the details of copulas adopted in this study are presented. Then, the details of drought characteristics, the definition of drought events by applying run theory and the procedures for the calculation of the SPEI and the estimation for bivariate return periods and the secondary return period using copula are explained. Later, the application of the methodology to the study region is presented and the results are discussed. Finally, brief conclusions of this study are presented.

\section{Study Area and Data Sources}

Songnen grassland is taken up as case study, which is drought vulnerability area in northeastern China. Songnen grassland is located between $43^{\circ} 30^{\prime}-48^{\circ} 05^{\prime} \mathrm{N}$ latitudes and $122^{\circ} 12^{\prime}-126^{\circ} 20^{\prime} \mathrm{E}$ longitude with 10.32 million $\mathrm{km}^{2}$ area. The location map of the study area and meteorological stations are given in Figure 1. It is surrounded by mountains on three sides, i.e., the Da Hinggan Mountains in the West, the Yilehuli Mountain and Xiaoxing 'an mountain in the North, Hangguangcai mountains in East, Songliao rivers watershed in the South. It is alluvial plains formed with Songhua River, Nenjiang and Taoer River and Huolinhe River. The elevation is $150-250 \mathrm{~m}$ above. Songnen grassland is a main part of the northeast China plain, which is among China's three Great Plains. Songnen grassland in northeastern China has arid climate condition with annual mean precipitation of $350-500 \mathrm{~mm}$ and drought degree reached 1.1-1.5. The annual evaporation in this area is $2-3$ times more than annual precipitation. In addition, the precipitation in this area is not only low but also uncertain. Due to the lack of precipitation, this region faces frequent severe droughts.
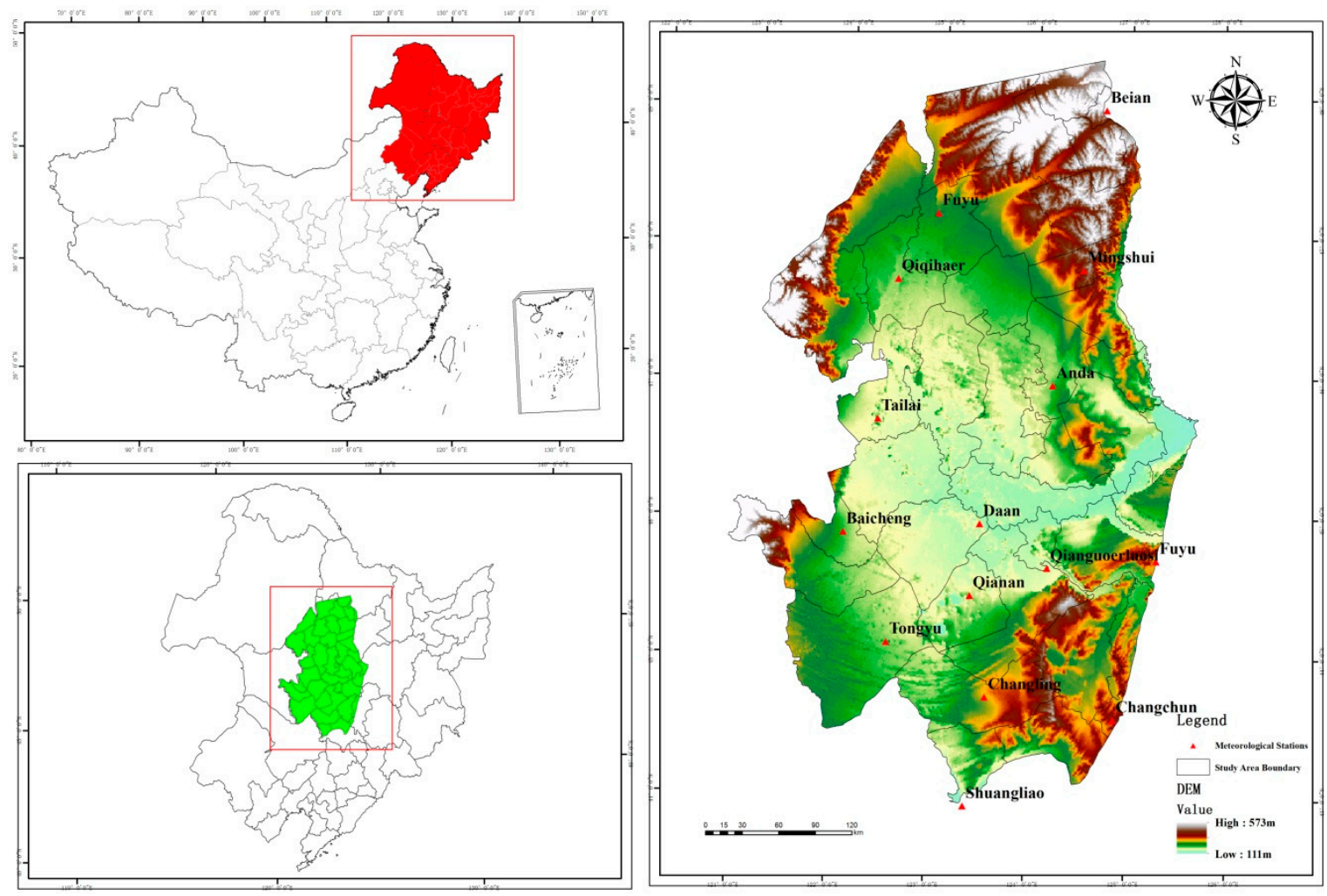

Figure 1. The location map of the research area and spatial distribution of meteorological stations.

The meteorological data used in this paper is derived from the China Meteorological Science Data Sharing Service Network (http://cdc.cma.gov.cn/) [21] and the ground weather data set provided by the Jilin Provincial Meteorological Bureau. There are 36 total meteorological stations in the study area. In this paper, we use RClimDex method and the standard data quality control (QC) process to check 
the weather data set covering from 1960 to 2014. The meteorological station which have negative daily temperature and precipitation amounts were exclude, based on the principle of the daily minimum temperature is larger than daily maximum temperature [22]. And, we apply the double-mass curve method to check the homogeneity for the both temperature data and precipitation data series for each meteorological station [23]. According to homogeneity result, the shortness of record years and missing dataset, 15 stations of Songnen grassland which have complete data from 1960 to 2014 are selected (Figure 1; Table 1). This data category includes the daily precipitation $(\mathrm{mm})$, average temperature $\left({ }^{\circ} \mathrm{C}\right)$, maximum temperature $\left({ }^{\circ} \mathrm{C}\right)$, minimum temperature $\left({ }^{\circ} \mathrm{C}\right)$, sunshine hours $(\mathrm{h})$, wind speed $(\mathrm{m} / \mathrm{s})$ and average relative humidity (\%) of each meteorological station.

Table 1. The basic information of each meteorological station in the study area.

\begin{tabular}{cccccc}
\hline NO. & Station Name & Station NO. & Longitude $\left(^{\circ}\right)$ & Latitude $\left.\mathbf{(}^{\circ}\right)$ & DEM $(\mathbf{m})$ \\
\hline 1 & Beian & 50656 & 126.52 & 48.28 & 269.70 \\
2 & Keshan & 50658 & 125.88 & 48.05 & 234.60 \\
3 & Fuyu & 50742 & 124.48 & 47.80 & 162.70 \\
4 & Qiqihaer & 50745 & 123.92 & 47.38 & 147.10 \\
5 & Mingshui & 50758 & 125.90 & 47.17 & 247.20 \\
6 & Tailai & 50844 & 123.42 & 46.40 & 149.50 \\
7 & Anda & 50854 & 125.32 & 46.38 & 149.30 \\
8 & Baicheng & 50936 & 122.83 & 45.63 & 155.30 \\
9 & Qianan & 50948 & 124.02 & 45.00 & 146.30 \\
10 & Qianguoerluosi & 50949 & 124.87 & 45.08 & 136.20 \\
11 & Tongyu & 54041 & 123.07 & 44.78 & 149.50 \\
12 & Changling & 54049 & 123.97 & 44.25 & 188.90 \\
13 & Fuyu & 54063 & 126.00 & 44.97 & 196.80 \\
14 & Changchun & 54161 & 125.22 & 43.90 & 236.80 \\
15 & Shuangliao & 54142 & 123.53 & 43.50 & 114.90 \\
\hline
\end{tabular}

\section{Methodology}

\subsection{The Standardized Precipitation Evapotranspiration Index (SPEI)}

Vicente-serrano [24] et al. constructed the SPEI, which has both the advantages of the SPI and the Palmer Drought Index (PDSI). The SPEI was derived from the SPI, which can be computed in different time scales to describe the different drought characteristics. Advanced from the SPI, the SPEI considers both the impact of precipitation and the potential evapotranspiration factors. The SPEI was widely applied on a monthly scale, daily scale and could identify the number of months and days in a drought event. The SPEI index is an internationally popular drought monitoring index. The main calculation process and detail expression is shown in [9]. This paper uses the SPEI package of $\mathrm{R}$ language to calculate SPEI-1, SPEI-3, SPEI-6 and SPEI-12 time scales.

\subsection{Run Theory}

Run theory is among the most effective methods for analyzing time series, which is proposed by Yevjevich [25]. The run theory refers to the occurrence of another type of event in the process of continuous occurrence of similar events, such as droughts, continuous rain-free days, rainy days, and alternating natural waters. This study uses the run theory to identify drought events which are characterized by drought duration and severity. As shown in Figure 2, a drought event is defined as the SPEI value is lower than a specified threshold $(-0.5)$ in the aggregation time period. As an indicator of drought, the SPEI can consider a negative run as a drought event, a drought event from start to finish as a drought duration (DD), and a negative run as the drought severity (DS) of the drought event. Figure 2 displays the schematic diagram of the process of the identification of drought events using run theory and the calculation formula is as follows [26]: 


$$
S=\left|-\sum_{i=1}^{d} \operatorname{SPEI}_{i}\right|<-0.5
$$

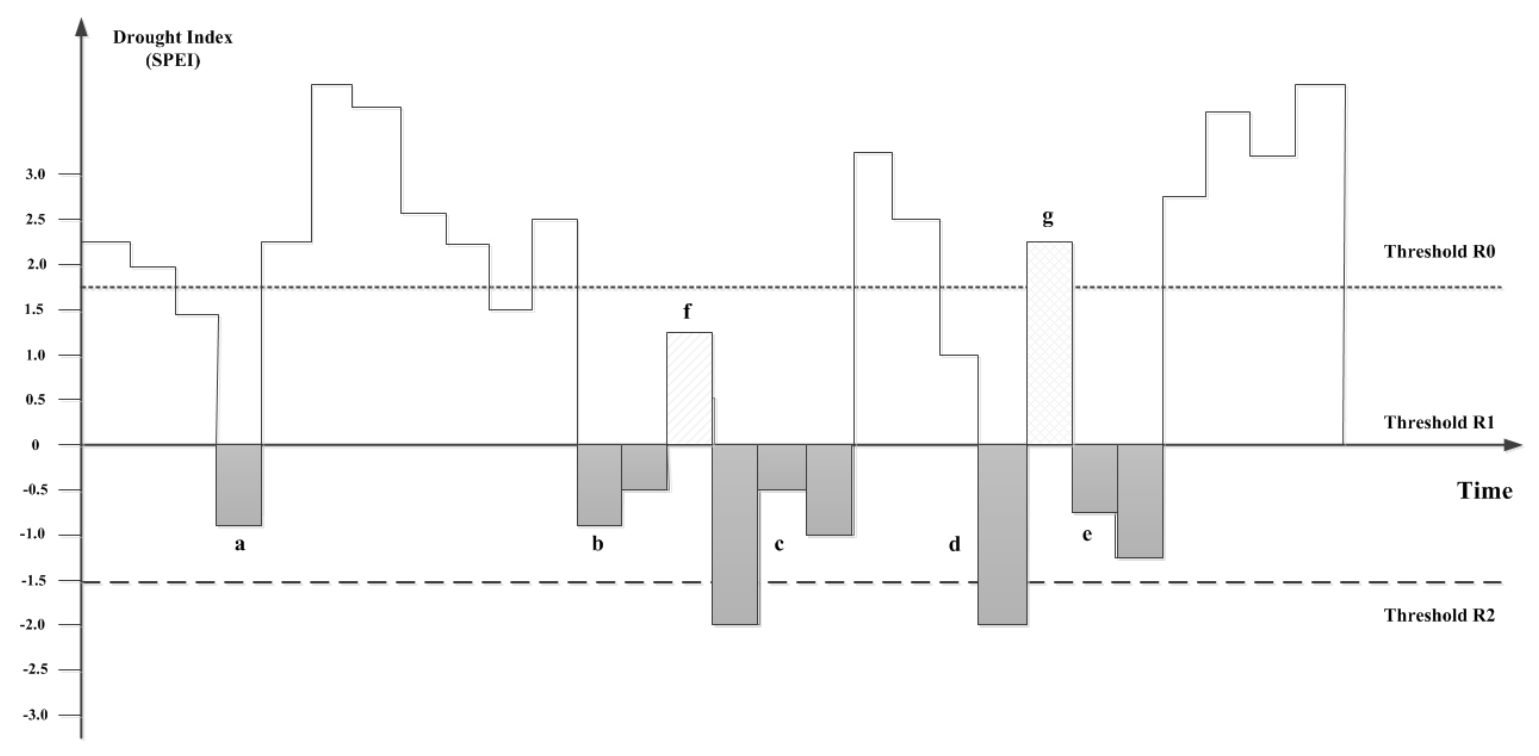

Figure 2. Identification of drought events based on the SPEI using run theory.

In this paper, we identify the grassland drought event based on the run theory during growing season from April to September, assuming the SPEI index threshold $R_{0}, R_{1}$ and $R_{2}$. The process of the identification of drought events is shown in Figure 2 and the identification step of the drought event is as follows. Firstly: preliminary judgment of the drought events. The SPEI consequence was divided by the threshold value $R_{1}$. When the SPEI value is less than $R_{1}$, the preliminary judgment for this period of drought is a, b, c, d and e. Secondly: handling small drought events. According to the first step preliminary result, we can filter the small drought events based on the threshold value $\mathrm{R}_{2}$. The drought event last only one unit time (such as a, d), and the SPEI value is lower than the threshold value $R_{2}$ (such as a), we defined this drought event as a small drought event and ignored in this study. For a drought event with an SPEI value that is less than $R_{2}$ (such as $d$ ), it is regarded as one drought event. Finally, merging drought events. The interval time last only one month between several drought events (such as b and c, $d$ and e) and the SPEI value is more than $R_{0}$ (such as $\mathrm{f}$ ), we can combine these two drought events into one drought event. If the SPEI value (such as g) is greater than $\mathrm{R}_{0}$, we can consider them independent drought events (such as d, e). Therefore, we identify 3 scales of drought events according the above steps as shown in Figure 2.

\subsection{Copula}

The copula function was first proposed by Sklar [27], which described a useful tool for linking multidimensional distribution with marginal distribution and constructing multivariate distribution functions. Copulas have been widely used to model bivariate distribution in hydrology, in meteorology, in finance, and more recently natural disaster risk management fields. More details about the mathematical details, assumptions, justifications and characteristics of various copula families can be found in references [28-30]. The specific calculation process is shown in references [31-34]. We have greater convenience to choose more suitable univariate distributions which are well fitted to the observed dataset and relatively simple to model a multivariate distribution, by using copulas.

The copula function states that if $F_{X, Y}(x, y)$ is a multivariate distribution function of two correlated random variables of $X$ and $Y$ with marginal distributions $F_{X}(x)$ and $F_{Y}(y)$, respectively, then there exists a copula $C$ such that: 


$$
F_{X, Y}(x, y)=C\left(F_{X}(x), F_{Y}(y)\right)=C(u, v)
$$

Copulas have many kinds of copula families that have been used to construct drought events. In this study, we selected the Frank, Gumbel-Hougaard (GH) and Clayton copula functions, which have been widely used to construct the joint distribution of droughts [13,35], to construct the multivariate drought model.

Define $u=F_{D}(d)$ and $v=F_{S}(s)$, and then those copula functions can be explained as follows:

$$
\begin{gathered}
F_{D, S}(d, s)=C(u, v)=\exp \left\{-\left[\left(-\ln ^{u}\right)^{\theta}+\left(-\ln ^{v}\right)^{\frac{1}{\theta}}\right]\right\} \\
F_{D, S}(d, s)=C(u, v)=\left(u^{-\theta}+v^{-\theta}\right)^{\frac{-1}{\theta}} \\
F_{D, S}(d, s)=C(u, v)=-\frac{1}{\theta} \ln \left[1+\frac{\left(e^{-\theta u}-1\right)+\left(e^{-\theta v}-1\right)}{\left(e^{-\theta}-1\right)}\right]
\end{gathered}
$$

The relationship $\theta$ parameter with the Kendall correlation coefficient $\tau$ is shown in the Table 2 .

$$
\tau=\left(C_{i}^{2}\right) \sum_{i<j}^{n} \operatorname{sgn}\left[\left(d_{i}-d_{j}\right)\left(s_{i}-s_{j}\right)\right]
$$

where $\left(d_{i}, s_{i}\right)$ is the joint distribution for the value of drought duration and drought severity.

$$
\operatorname{sgn}(x)=\left\{\begin{array}{ccc}
1 & \text { if } & x>0 \\
0 & \text { if } & x=0 \\
-1 & \text { if } & x<0
\end{array}\right.
$$

The fitting accuracy of the results of the three copulas was evaluated by the root mean square error (RMSE) [36] and Akaike Information Criterion (AIC) [37,38].

Table 2. Relationship between $\theta$ and $\tau$ for different copula types.

\begin{tabular}{cc}
\hline Copula Types & The Relationship between $\theta$ and $\tau$ \\
\hline G-H & $\tau=1-\frac{1}{\theta}(\theta \geq 1)$ \\
Clayton & $\tau=\frac{\theta}{(\theta+2)}(\theta>0)$ \\
Frank & $\tau=1+\frac{4}{\theta}\left(\frac{1}{\theta} \int_{0}^{\theta} \frac{1}{e^{t}-1} d t-1\right)(\theta \neq 0)$ \\
\hline
\end{tabular}

A suitable marginal distribution model well fitted to each drought property is required before building the bivariate copula model. Therefore, we used SPEI values to separate and selected gamma distribution and Generalized Extreme Value distribution (GEV) for drought duration and severity characteristics, respectively, which are frequently used to fit the distribution of droughts and floods [10,39]. Then, the parameters of the two distributions were evaluated by the maximum likelihood method to select the appropriate distribution for each SPEI series. Finally, we selected the probability distribution function, with the highest goodness-of-fit for each station based on the Kolmogorov-Smirnov (K-S) goodness-of-fit test [40]. In this study, we choose a confidence level 95\% to judge fit result. We found that drought severity is best described by the generalized extreme value (GEV) distribution, whereas drought duration is best fitted by gamma distribution. In the previous study, most scholars [41,42] argue that exponential distribution is more suitable to fit the frequency of drought duration, but the result shows that gamma distribution is a better fit than exponential distribution in Songnen Grassland, implying that the best marginal distribution function for different 
study regions may be different. Therefore, the choice of the correct marginal distribution function before drought risk analysis is necessary.

\subsection{Return Periods}

\subsubsection{The Bivariate Return Periods}

The return period is referred to as the equal time or mean inter-arrival time between two consecutive intervals of drought events. More details about return periods are introduced and outlined in references [20,43-45]. In this paper, the return period of drought severity (s) and drought duration (D) can be expressed as follows:

$$
\begin{gathered}
T(D)=\frac{E(L)}{P(D>d)}=\frac{E(L)}{1-F_{D}(d)} \\
T(S)=\frac{E(L)}{P(S>s)}=\frac{E(L)}{1-F_{S}(s)}
\end{gathered}
$$

where $T(D)$ is the return period for drought duration, $T(S)$ is the return period of drought severity, and $E(L)$ is the exceeded drought inter-arrival time.

There are two scenarios of the bivariate return period of drought risk in terms of drought duration and drought severity distribution, which are defined as $T_{\cup}(d, s)$ and $T_{\cap}(d, s)$. Then, the bivariate return periods related to these scenarios are computed as follows [46]:

$$
\begin{aligned}
& T_{\cup}(d, s)=\frac{E(L)}{P(D>d \cup S>s)}=\frac{E(L)}{1-F_{D, S}(d, s)}=\frac{E(L)}{1-C\left(F_{D}(d), F_{S}(s)\right)} \\
& T_{\cap}(d, s)=\frac{E(L)}{P(D>d \cap S>s)}=\frac{E(L)}{1-F_{D}(d)-F_{S}(s)+C\left(F_{D}(d), F_{S}(s)\right)}
\end{aligned}
$$

where $T_{\cup}(d, s)$ is the return period of $D \geq d$ or $S \geq s$, and $T_{\cap}(d, s)$ is the return period of $D \geq d$ and $S \geq s$. The bivariate return period of drought duration and drought severity can be easily estimated by the above series of formulas respectively.

\subsubsection{The Secondary Return Periods}

For a given copula function, different variable combinations of the boundary value probability distribution function may have the same cumulative probability $q$, namely $C\left(u_{x}, v_{x}\right)=q$ and $C\left(u_{y}, v_{y}\right)=$ $q$. In the drought risk analysis research field, researchers are more interested in supercritical conditions like $C(u, v)>q$ for a random event $(u, v)$ when the cumulative probability $q$ as an indicator and the indicator affects the same result. Salvadori [47] defines the secondary return periods by Kendall distribution functions $\left(K_{C}\right)$ expressed as follow:

$$
K_{C}(q)=P(C(u, v) \leq q)
$$

The $K_{C}$ expression of Archimedean copula is:

$$
K_{C}(q)=q-\frac{\varphi(q)}{\varphi^{\prime}\left(q^{+}\right)}
$$

where $\varphi^{\prime}\left(q^{+}\right)$is the right differential of $\varphi^{\prime}\left(q^{+}\right)$.

The expression of "or" the joint return period $\left(\rho_{q}^{\vee}\right)$ of the secondary return period is:

$$
\rho_{q}^{\vee}=\frac{\mu_{T}}{1-K_{C}(q)}
$$


They also indicated that the secondary return period gives precise information for conducting a risk analysis and may also be a useful tool for conducting numerical simulations [8]. In this study, we select the secondary return period for the risk analysis of drought for Songnen grassland in northeastern China.

\subsection{Inverse Distance Weighted Interpolation Method}

We can approximate the more complex relationship between factors through the construct function of the interpolation method. It is a generalized least squares regression method. The Inverse Distance Weighted (IDW) is among the most important content of geostatistics science and among the most popular interpolation methods. The IDW method is based on a similar procedure to decide the weighted average by the distance between the interpolation points and the samples. The formula is expressed as follows:

$$
Z(x)=\sum_{i=1}^{n} \lambda_{i} \bullet Z\left(x_{i}\right)
$$

where $Z(\chi)$ is the calculated value, $n$ is the sample scale, and $\lambda_{i}$ is the weight of a sample point.

\section{Results}

\subsection{Analysis of Drought Characteristics}

In this study, we used Qian'an station as a case study in order to clarify and validate the computation procedure. Based on the research of Songnen grassland by Professor Zhu Yancheng and Professor Li Jiandong, the grass growing stage generally lasts from April to October. The SPEI-6 scales calculated by using the six months temperature and the precipitation sequence data from April to October which covers the entire grass growing season of each meteorological station, and researcher found that the SPEI-6 scale is more suitable for the analysis of drought [48]. Therefore, the SPEI-6 scale was selected to identify the drought events during the growth period of Songnen grassland, and the run theory was used to define the statistics for severe drought events, which is $S P E I<-0.5$.

The SPEI can depict the succession of drought events at different time scales. Furthermore, according to the different grades of drought (Table 1), it can assess the characteristics of different types of drought changes at different time scales in the research area. As can be seen from Figure 3, drought events change frequently in a short time period of one and three months, and are very sensitive to changes in short-scale temperature and precipitation (Figure 3a,b). The larger SPEI time scale, the longer alternate frequency of drought events interval has occurred. Figure $3 c$,d shows that drought events have weak responses to short-scale temperature and precipitation in six and twelve months, and drought event changes are relatively stable. Songnen Grassland suffers alternating periods of drought about four years, such as in 1968-1972 and 2001-2005, with six years of drought periods occurring in 1979-1985.

Simultaneously, the spatial distribution of drought characteristics, i.e., average duration and severity, maximum severity and number of drought events, corresponds to the SPEI values of a 6 month time interval as shown in Figure 4 as well. Figure 4a shows the spatial patterns of average drought duration calculated by the SPEI values of a 6 month time interval. There are more significant differences between the spatial distributions of average drought duration compared with other drought characteristics. The spatial patterns of average drought duration indicate that the Qian'an county tend to experience relatively long-lasting drought events. The spatial patterns of average drought severity indicate that the middle parts of the grassland experienced more intense drought events, i.e., Mingshui county, Qinggang city, Daqing city and Zhaoyuan county. And severe drought was also found in Bei'an city. However, fewer intense droughts are seen in Baicheng city, Taonan city, Changling county and Shuangliao city (Figure 4b). As shown in Figure 4c, it is specifically obvious that Bai'an city has experienced more severe droughts. No obvious spatial distribution for the maximum severity 
characteristic of drought events was found. For the number of drought events, a higher number of droughts was found in Keshan county, Baicheng city, Taonan city, Changling county and Shuangliao city, while a lower number of droughts was seen in Songyuan city and Bei'an city for SPEI-6 month series (Figure $4 \mathrm{~d}$ ).

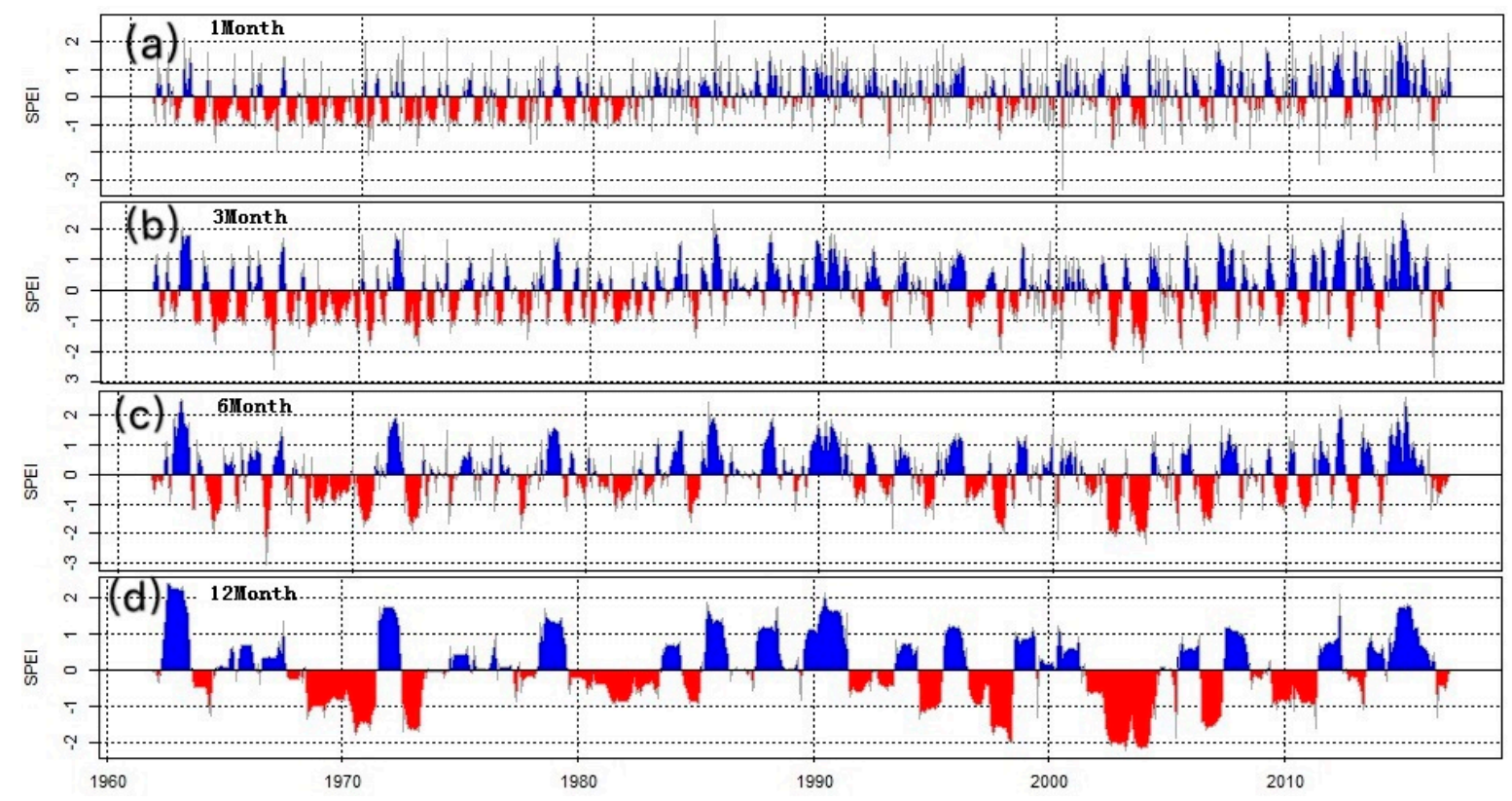

Figure 3. The different time scale SPEI of Qian'an station (1960-2014). (a) 1 month time scale(SPEI-1); (b) 3 month time scale(SPEI-3); (c) 6 month time scale (SPEI-6); (d) 12 month time scale(SPEI-12).
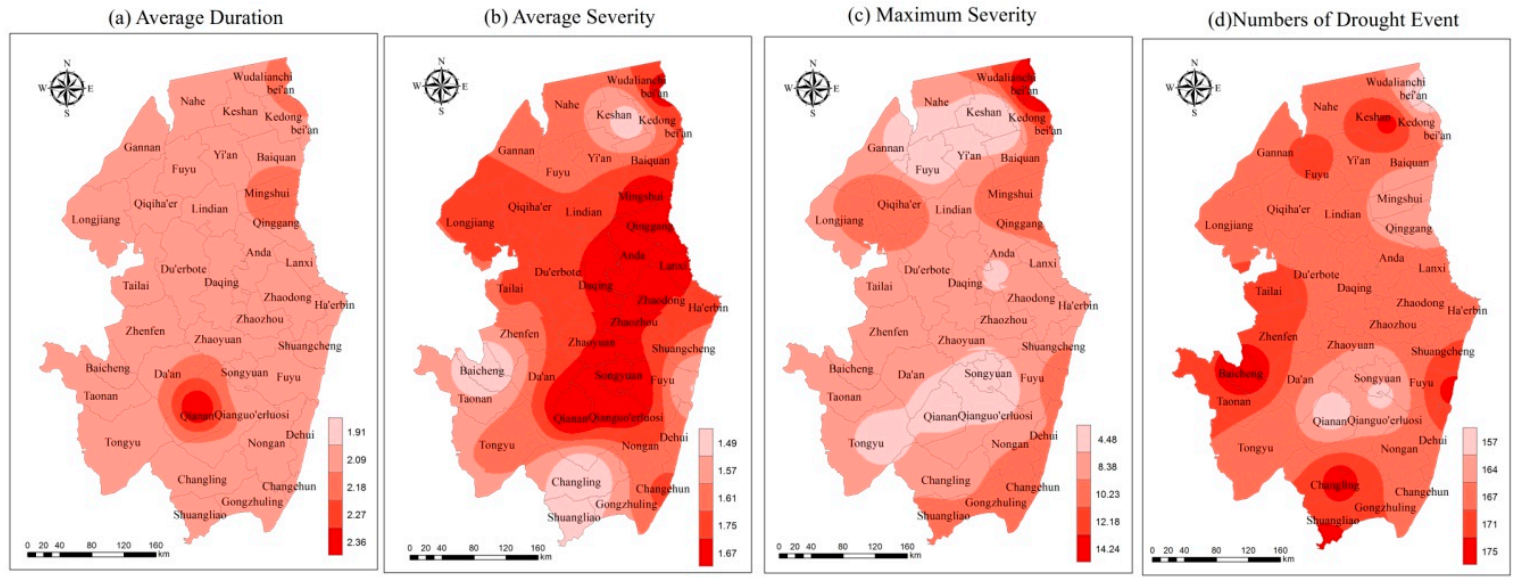

Figure 4. Spatial distributions of (a) average duration, (b) average severity, (c) maximum severity, and (d) number of drought events.

\subsection{Correlation between Drought Duration and Drought Severity}

By calculating the Spearman's rank correlation coefficient, with details in ref [49], of drought duration and drought severity, we found that there is a strong correlated relationship for 15 meteorological stations in the period 1960-2014 in Songnen grassland in northeastern China. The correlation coefficient between drought duration and drought severity is $0.7584-0.6505$, among them, the Mingshui station has the highest correlation, which is 0.7584 , and Qianguo station has the lowest correlation coefficient, which is 0.6505 . The scatter distribution of the drought duration and drought severity of Qian'an station is shown in Figure 5. 


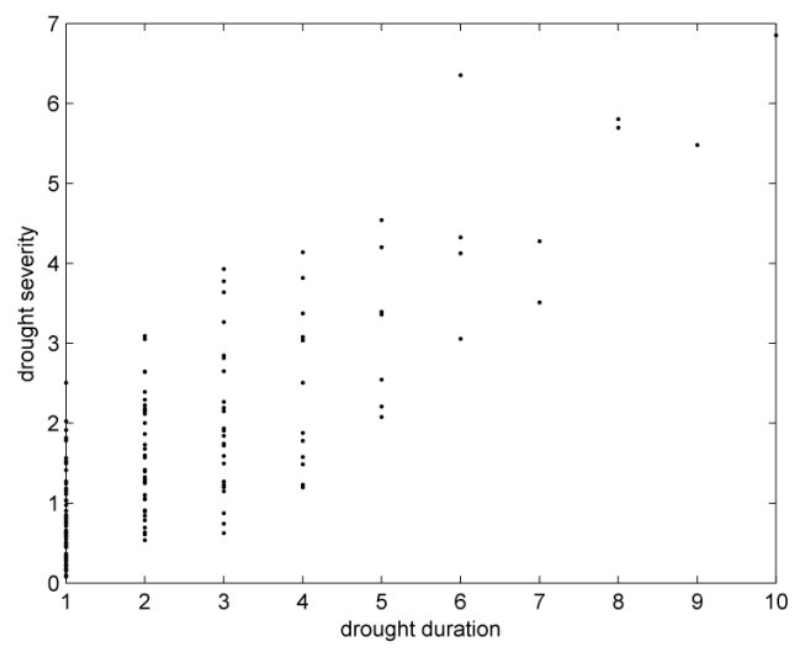

Figure 5. Scatter plots of observed drought duration against drought severity for Songnen grassland in northeastern China.

\subsection{The Selection of the Appropriate Copula}

Because different copula functions represent different related association structures, and the choice of the copula function will directly affect the result of the analysis and statistical inference, therefore, choosing the best copula function is a very important task in our study. In this paper, we selected Clayton, Frank and Gumbel-Hougaard copula as optimal copulas for determining the joint distribution of drought duration and drought severity at all the meteorological stations. We used Kendall's tau coefficient to measure the association between drought duration and drought severity. The parameters are used to the observe copula distributions due to confirming the best-fitted bivariate copula family and to imitate the dependency between drought duration and severity. The results for Kendall's tau coefficient and parameter estimation for the 15 stations in Songnen grassland in northeastern China are shown in Table 3. Furthermore, the copula families are determined by the RMSE and AIC (Table 3). As shown in Table 3, it is obvious that the Frank copula distribution produces minimum error and the lowest value of RMSE and AIC, which indicates that the Frank copula is the best-fitted joint distribution of drought duration and drought severity. Figure $6 a, b$ illustrates the surface plot and contour lines of the joint cumulative probability for drought duration and drought severity using the Frank copula respectively. According to the above analysis, we used the Frank copula function to link the marginal distribution functions, gamma distribution and GEV distribution, which can effectively describe the relevant joint distribution of drought duration and drought severity for Songnen grassland in northeastern China.

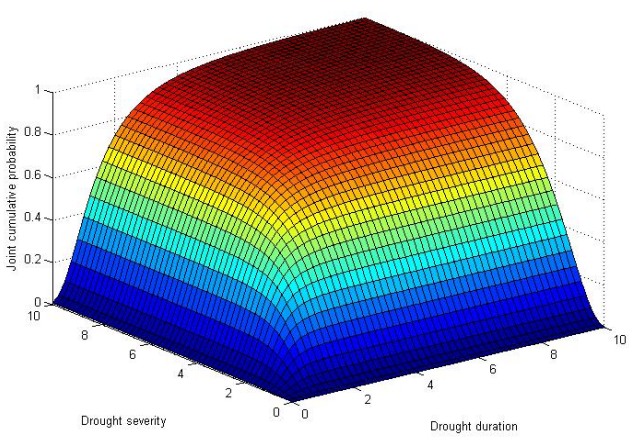

(a)

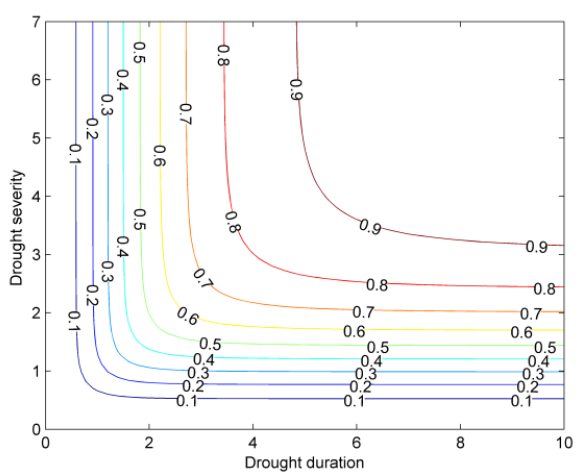

(b)

Figure 6. Surface plot (a) and contour lines (b) of the joint cumulative probability of drought duration and drought severity using the Frank Copula, using observed drought data obtained from Qian'an station. 
Table 3. The values of the Kendall's tau coefficient, parameters, Root Mean Square Error (RMSE), and Akaike Information Criterion (AIC) for 15 meteorological stations and three copula functions fitted to drought variables derived from drought events defined on the basis of SPEI-6.

\begin{tabular}{|c|c|c|c|c|c|c|c|c|c|c|c|}
\hline \multirow{3}{*}{ NO. } & \multirow{3}{*}{$\begin{array}{l}\text { Station } \\
\text { Name }\end{array}$} & \multirow{3}{*}{$\begin{array}{l}\text { Kendall's Tau } \\
\text { Coefficient }\end{array}$} & \multicolumn{9}{|c|}{ Copula Family } \\
\hline & & & \multicolumn{3}{|c|}{ Clayton } & \multicolumn{3}{|c|}{ Frank } & \multicolumn{3}{|c|}{ G-H } \\
\hline & & & Parameter & RMSE & AIC & Parameter & RMSE & AIC & Parameter & RMSE & AIC \\
\hline 1 & Qian'an & 0.6056 & 1.52 & 0.11 & -298.26 & 6.10 & 0.10 & -306.25 & 1.97 & 0.11 & -299.80 \\
\hline 2 & Keshan & 0.5656 & 1.33 & 0.12 & -311.66 & 5.27 & 0.12 & -319.93 & 1.82 & 0.12 & -315.29 \\
\hline 3 & Qianguo & 0.5205 & 1.14 & 0.12 & -288.75 & 4.64 & 0.12 & -293.91 & 1.76 & 0.12 & -291.55 \\
\hline 4 & Bei'an & 0.5814 & 1.29 & 0.13 & -275.32 & 5.39 & 0.12 & -283.40 & 1.80 & 0.13 & -277.19 \\
\hline 5 & Shuangliao & 0.6061 & 1.29 & 0.15 & -282.58 & 6.04 & 0.14 & -294.89 & 1.96 & 0.14 & -288.87 \\
\hline 6 & Anda & 0.5333 & 1.11 & 0.15 & -282.58 & 5.01 & 0.14 & -294.89 & 1.75 & 0.14 & -288.87 \\
\hline 7 & Fuyu & 0.5463 & 1.17 & 0.13 & -297.52 & 5.05 & 0.13 & -306.53 & 1.71 & 0.13 & -298.81 \\
\hline 8 & Fuyu & 0.5391 & 1.15 & 0.14 & -286.19 & 4.76 & 0.13 & -291.78 & 1.78 & 0.14 & -288.66 \\
\hline 9 & Mingshui & 0.6182 & 1.38 & 0.13 & -276.18 & 6.17 & 0.12 & -285.56 & 1.97 & 0.13 & -278.88 \\
\hline 10 & Tailai & 0.5652 & 1.19 & 0.14 & -287.44 & 5.28 & 0.13 & -297.86 & 1.81 & 0.13 & -292.36 \\
\hline 11 & Baicheng & 0.5581 & 1.16 & 0.14 & -299.62 & 5.23 & 0.13 & -311.62 & 1.86 & 0.13 & -307.93 \\
\hline 12 & Tongyu & 0.5939 & 1.32 & 0.14 & -280.95 & 5.87 & 0.13 & -290.24 & 2.00 & 0.13 & -286.31 \\
\hline 13 & Changling & 0.6035 & 1.32 & 0.16 & -272.96 & 6.33 & 0.15 & -286.02 & 1.90 & 0.16 & -275.71 \\
\hline 14 & Changchun & 0.5759 & 1.28 & 0.13 & -285.69 & 5.57 & 0.12 & -297.61 & 1.79 & 0.13 & -289.20 \\
\hline 15 & Qiqiha'er & 0.5764 & 1.26 & 0.13 & -291.12 & 5.53 & 0.12 & -301.44 & 1.91 & 0.12 & -297.48 \\
\hline
\end{tabular}




\subsection{Spatial Characteristics of Drought Duration and Severity for Different Return Periods}

In this study, the two variables of drought duration and drought severity describe the drought characteristics. Drought events with long duration and large severity have a serious effect on Songnen grassland. The spatial distributions of the drought duration and drought severity of different drought events corresponding to a return period of 5, 10, 20 and 50 years in Songnen grassland are shown in Figures 7 and 8, respectively.

It was found that most areas in Songnen grassland are characterized by 5 year return period of drought duration (Figure 7a). Also, the spatial distributions of a 10, 20, and 50 year return period of drought duration in Songnen grassland are more similar. According to the spatial distributions of a 5,10,20, and 50 year return period of drought severity, we have seen that the intensity of drought severity decreases with an increasing return period, except for the severity of a 20 year return period of drought severity. We also found that Songnen grassland is mostly dominated by the 20 year return values of drought severity (Figure 8c).
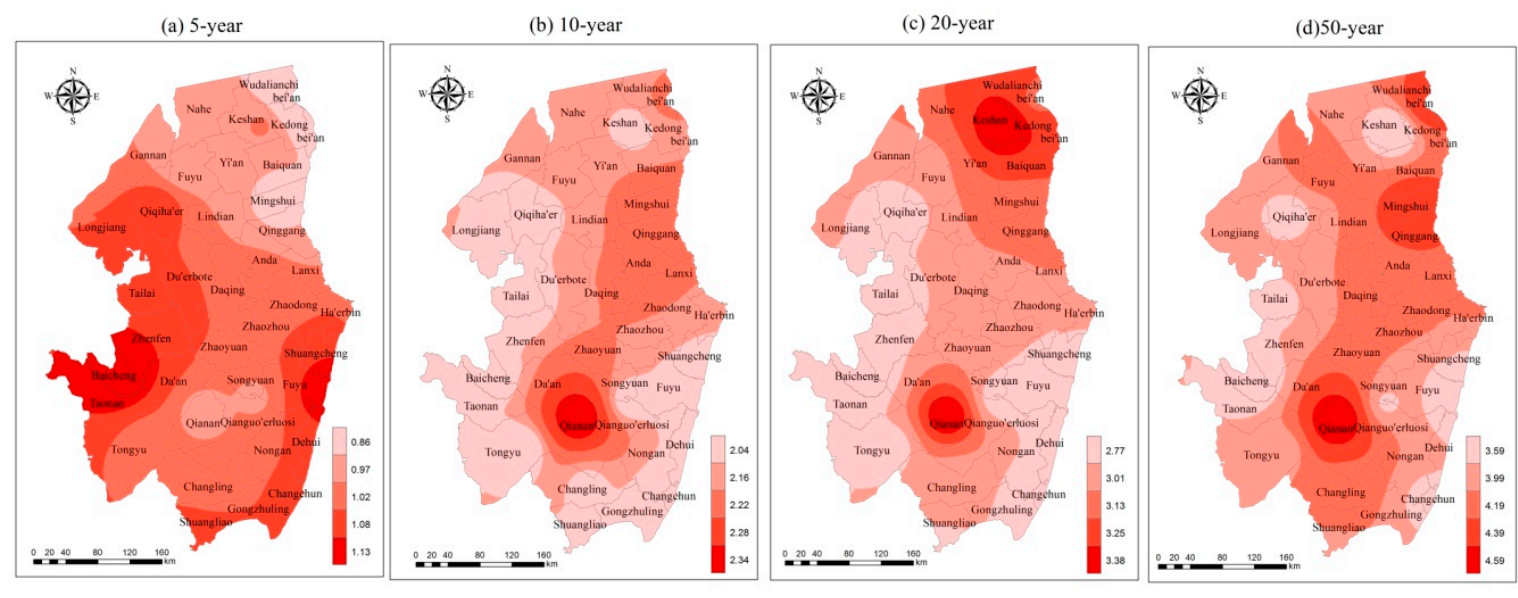

Figure 7. Spatial distribution of the drought duration according to different return periods in Songnen grassland in northeastern China.
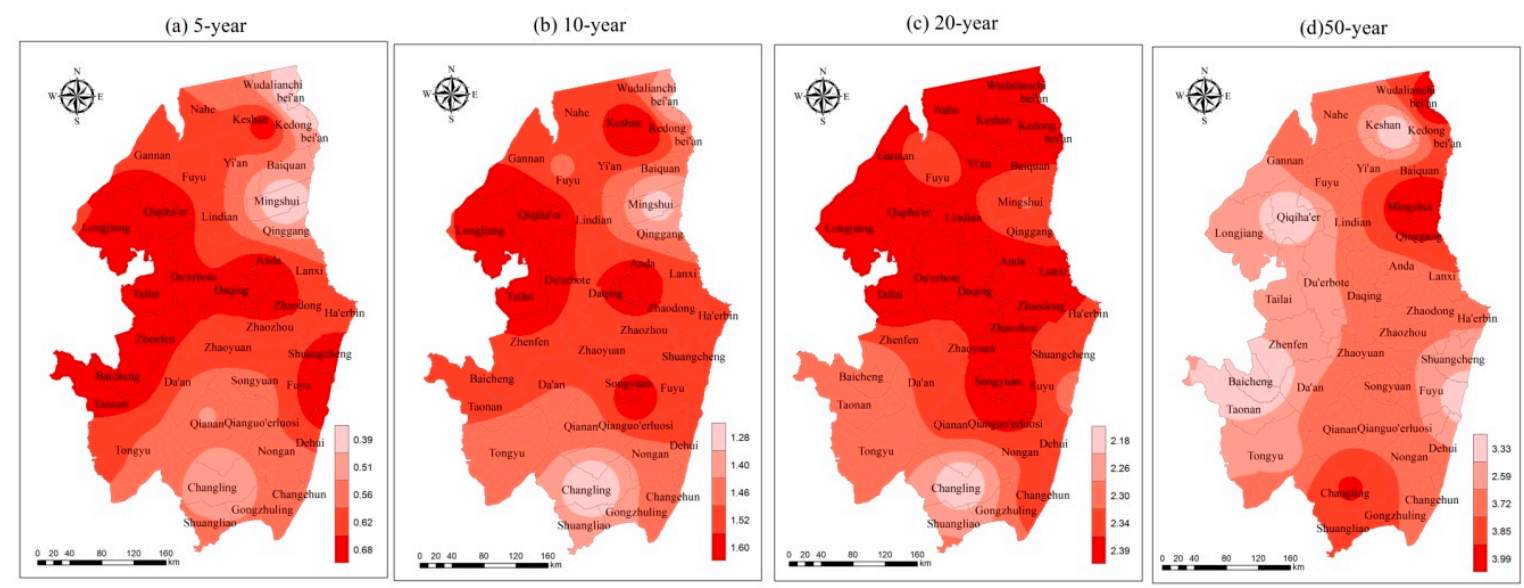

Figure 8. Spatial distribution of the drought severity according to different return periods in Songnen grassland in northeastern China.

\subsection{Spatial Distributions of Joint Return Periods and Secondary Return Period}

We calculated the joint return periods and corresponding secondary return periods for 15 meteorological stations, analyzed the return periods for each stations' droughts and conducted IDW interpolation processing in order to obtain the spatial distribution of different joint return periods and secondary return periods in Songnen grassland in northeastern China. In this paper, we considered two 
kinds of scenarios for the analysis of joint return periods and corresponding secondary return periods, such as (1) drought duration was 6 months with a drought severity of 5.5; and drought duration was 9 months with a drought severity of 7.5. The spatial pattern of the return periods for the two scenarios is shown in Figures 9 and 10, respectively.

The spatial pattern of the return periods of the joint return period of "or", joint return period of "and" and the secondary return periods of "or" the joint return period with 6 months drought duration and 5.5 drought severity for Songnen grassland in northeastern China for the first scenario is shown in Figure $9 a-c$. Figure $9 b, c$ indicate that a similar area of low joint return period (high risk of drought area) characterized by a duration of 6 months connection with a drought severity of 5.5 can be found in Bei'an county, Mingshui county, Qian'an county and Changling city, and also in Shuangliao city. It also can be observed from Figure $9 b, c$ that a similar area of high joint return period (low risk of drought area) can be found in Keshan county, Qiqiha'er city and Taonan city. The high risk of drought area which is located in Qiqiha'er city in the secondary return periods of "and" the joint return period compared with the first return period of "or" the joint return period has expanded. As for the return periods of drought with a duration of 6 months and drought severity of 5.5 (Figure 9a,c), larger regions, when compared to the spatial pattern of "or" the joint return period and secondary return periods of "or" the joint return period, have similar high and low risk center. Vandenberghe et al. [50] suggested that the secondary return periods of "or" the joint return period compared with the first "or" the joint return can be more realistic description of the risk of drought events. Therefore, the results of the secondary return period of "or" the joint return period would be more accurate.

(a)

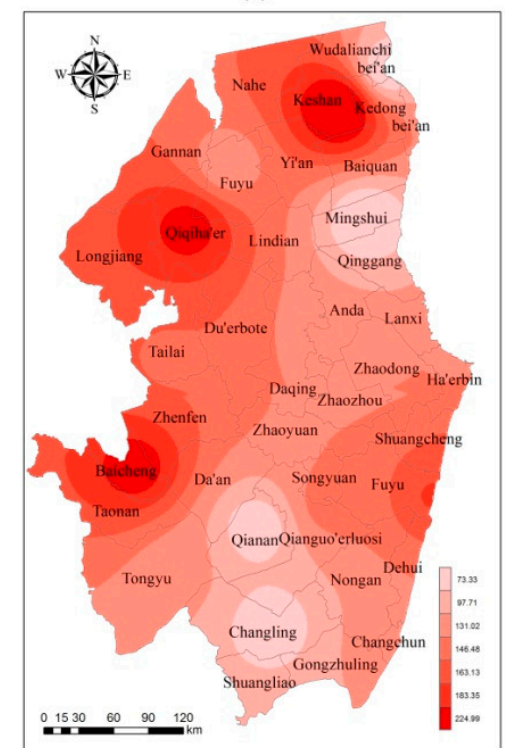

(b)

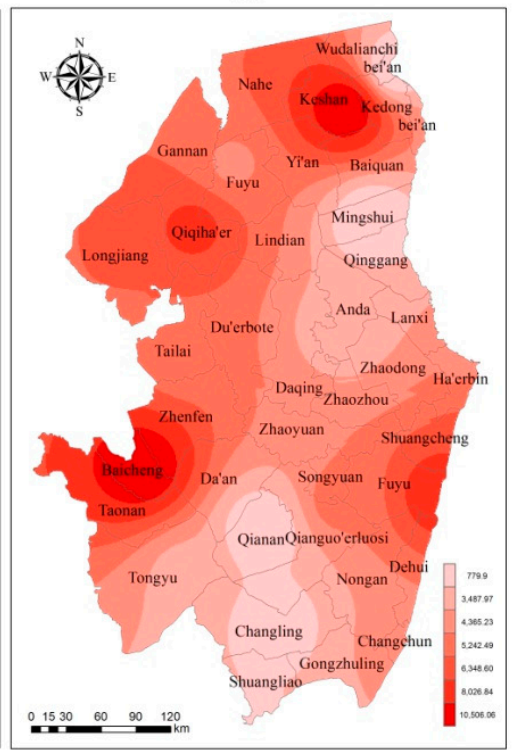

(c)

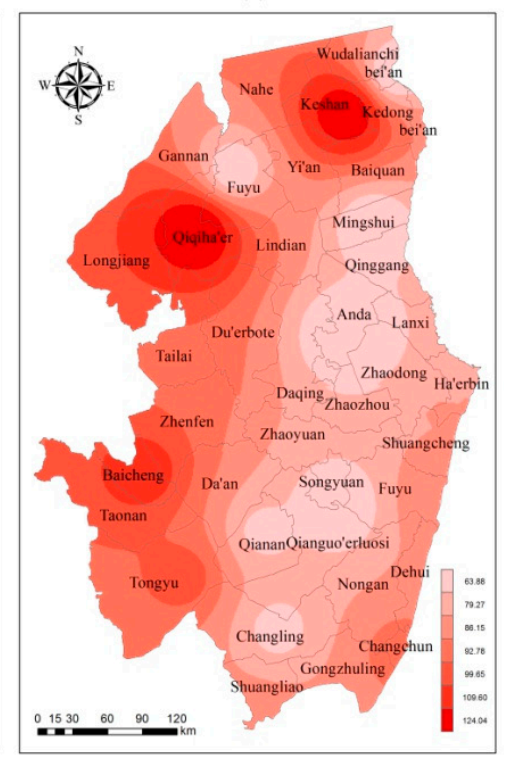

Figure 9. Spatial distribution of (a) the joint return period of "or"; (b) the joint return period of "and"; (c) the droughts joint return period of the secondary return periods of "or" with a drought duration of 6 months and the drought severity of 5.5.

The spatial pattern of the return periods including secondary return periods of a drought duration of 9 months related to a higher drought severity of 7.5 of Songnen grassland in northeastern China for the second scenario is shown in Figure 10a-c. Similar features for the spatial pattern of the return periods of droughts related with longer durations and higher severities across Songnen Grassland in northeastern China can be identified. It can be seen from Figure 10a,c that two similar high-risk regions of drought characterized by drought duration of 9 months with drought a severity of $7.5 \mathrm{can}$ be found in Keshan county, Longjiang county and in Qiqiha'er city. However, the area of high-risk regions located in Qiqiha'er city in the secondary return period of "or" was greater than the joint return 
period. A lower drought risk can be seen in Bei'an county, northeast of Gannan county and west of Nahe city, and Changling county, Shuangliao city and also in Mingshui county.

(a)

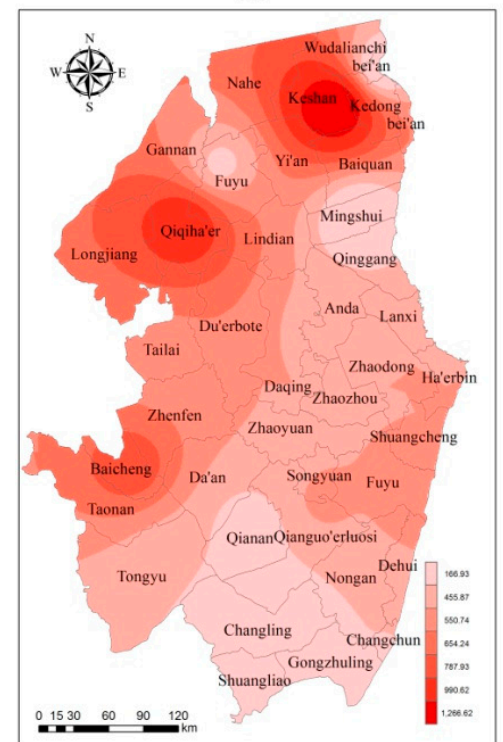

(b)

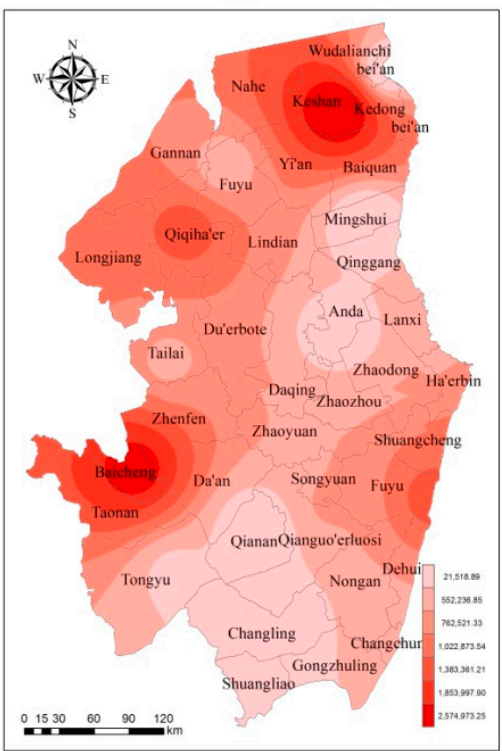

(c)

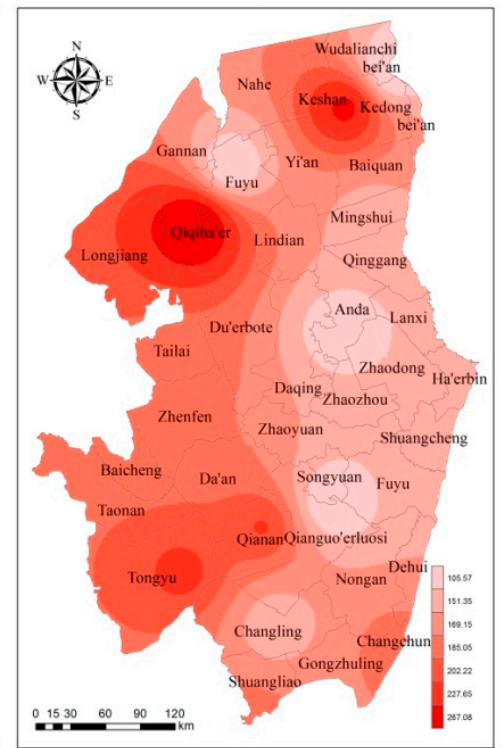

Figure 10. Spatial distribution of (a) the joint return period of "or"; (b) the joint return period of "and"; (c) the droughts joint return period of the secondary return periods of "or" with a drought duration of 9 months and the drought severity of 7.5.

\section{Conclusions and Discussion}

Drought is the most severe disasters among the all natural disaster to affect pastoral areas like Songnen grassland in northeastern China. Therefore, a deep and complete understanding and analysis of the frequency of drought characteristics associated with drought severity and duration is essential for drought risk analysis, which is an important part of risk management. In this paper, 15 daily meteorological data stations covering the period 1960-2014 are analyzed using probability distribution functions and copula. The drought events are characterized by severity and duration and defined by the run theory and the calculated SPEI. Three Archimedean copulas were chosen to model the joint distributions for the drought characteristics. The significant conclusions are expressed as follows:

(1) By evaluating the marginal distribution for drought variables and using the Kolmogorov-Smirnov (K-S) goodness-of-fit test, we found that the drought duration is best investigated by gamma distribution, while the drought severity is best investigated by the generalized extreme value (GEV) distribution. This result obtained is different from the research carried out by Mirabbasi et al. [51], who assume that gamma and exponential distributions are appropriate for the univariate marginal distribution of drought variables. The result indicates that different drought indicators and criterions for drought events may determine the different methods chosen for the marginal distribution of drought variables [52].

(2) To investigate the joint performance of drought duration and drought severity, the Frank, G-H and Clayton copulas were employed and their results were assessed by RMSE and AIC tests. The RMSE and AIC tests were showed that Frank copula is the best performing model for modeling the joint dependence structure of the drought duration and drought severity of the study region.

(3) The two kinds of the return periods of drought events are analyzed according to the two scenarios. Then, the spatial distributions of two kinds of the return periods of drought events considering different return periods are analyzed. In this study, we investigated two scenarios of drought events. Results indicate that there is a higher risk of droughts in Keshan county, Longjiang county, Qiqiha'er city, Taonan city and Baicheng city. There is a relatively lower risk of drought in Bei'an 
city, Mingquan county, Qinggang county and Qian'an county, and also in Changling county and Shaungliao city.

By calculating the secondary return periods and considering all possible scenarios in this study, we found that the secondary return periods is the best indicator for drought risk analysis. It is our hope that the probabilistic property analysis can supply useful tools for natural resource management, especially in arid and semi-arid regions. However, the risk analysis of the drought method used in this study is for practical purposes for instructing drought risk management.

Author Contributions: Conceptualization, J.Z. and Y.B.; formal analysis, R.W.; funding acquisition, J.Z., Y.B. and R.W.; methodology, E.G.; project administration and software supervision, J.Z.; visualization, R.W.; writing—original draft, R.W.; writing—review \& editing, R.W.

Funding: This research was funded by the National Science Foundation of China, grant number 41571491 and 41371495; The Science and Technology Development Planning of Jilin Province, grant number 20190303018SF; The Science and Technology Planning of Changchun, grant number 19SS007; The China Special Fund for Meteorological Research in the Public Interest, grant number GYHY201506001-6; the Fundamental Research Funds for the Central Universities of China, grant number 2412016KJ046; National Natural Science Foundation of China, grant number 61631011; 13th Five-Year" National Key R\&D Program, grant number 2017YEE0109100 and the Liaoning Normal University Ph.D. Startup Fund, grant number 1202/203070091807. And The APC was funded by all of them.

Acknowledgments: The authors are grateful to the anonymous reviewers for their insightful and helpful comments to improve the manuscript.

Conflicts of Interest: The authors declare no conflict of interest.

\section{References}

1. Shen, J.G. China Meteorological Disaster Ceremony: Inner Mongolia Volume; Meteorological Press: Beijing, China, 2008.

2. Palmer, W. Meteorological Drought; Research Paper, NO. 45; U.S. Department of Commerce Weather Bureau: Washngton, DC, USA, 1965; 58p.

3. Mckee, T.B.; Doesken, N.J.; Kleist, J. The relationship of drought frequency and duration to time scales. In Eighth Conference on Applied Climatology; American Meteorological Society: Boston, MA, USA, 1993.

4. Kite, G.W. Frequency and Risk Analyses in Hydrology; Water Resources Publications: Fort Collins, CO, USA, 1988.

5. Byun, H.R.; Wilhite, D.A. Objective Quantification of Drought Severity and Duration. J. Clim. 1999, 12, 2747-2756. [CrossRef]

6. Keyantash, J.A.; Dracup, J.A. An aggregate drought index: Assessing drought severity based on fluctuations in the hydrologic cycle and surface water storage. Water Resour. Res. 2004, 40, 333-341. [CrossRef]

7. National Standard of People's Republic of China GB/T 20481-2006. Classification of Meteorological Drought; Beijing China Standard Press: Beijing, China, 2006. (In Chinese)

8. Tsakiris, G.; Pangalou, D.; Vangelis, H. Regional Drought Assessment Based on the Reconnaissance Drought Index (RDI). Water Resour. Manag. 2007, 21, 821-833. [CrossRef]

9. Vicenteserrano, S.M.; Beguería, S.; Lópezmoreno, J.I. A multiscalar drought index sensitive to global warming: The standardized precipitation evapotranspiration index. J. Clim. 2010, 23, 1696-1718. [CrossRef]

10. Shiau, J.T. Fitting Drought Duration and Severity with Two-Dimensional Copulas. Water Resour. Manag. 2006, 20, 795-815. [CrossRef]

11. Song, S.; Singh, V.P. Frequency analysis of droughts using the Plackett copula and parameter estimation by genetic algorithm. Stoch. Environ. Res. Risk Assess. 2010, 24, 783-805. [CrossRef]

12. Ganguli, P.; Reddy, M.J. Risk Assessment of Droughts in Gujarat Using Bivariate Copulas. Water Resour. Manag. 2012, 26, 3301-3327. [CrossRef]

13. Ma, M.; Song, S.; Ren, L.; Jiang, S.; Song, J. Multivariate drought characteristics using trivariate Gaussian and Student t copulas. Hydrol. Process. 2013, 27, 1175-1190. [CrossRef]

14. Saghafian, B.; Mehdikhani, H. Drought characterization using a new copula-based trivariate approach. Nat. Hazards 2014, 72, 1391-1407. [CrossRef] 
15. Serinaldi, F.; Bonaccorso, B.; Cancelliere, A.; Grimaldi, S. Probabilistic characterization of drought properties through copulas. Phys. Chem. Earth Parts A/B/C 2009, 34, 596-605. [CrossRef]

16. Yusof, F.; Hui-Mean, F.; Suhaila, J.; Yusof, Z. Characterisation of Drought Properties with Bivariate Copula Analysis. Water Resour. Manag. 2013, 27, 4183-4207. [CrossRef]

17. Masud, M.B.; Khaliq, M.N.; Wheater, H.S. Analysis of meteorological droughts for the Saskatchewan River Basin using univariate and bivariate approaches. J. Hydrol. 2015, 522, 452-466. [CrossRef]

18. Salvadori, G.; Michele, C.D. Multivariate real-time assessment of droughts via copula-based multi-site Hazard Trajectories and Fans. J. Hydrol. 2015, 526, 101-115. [CrossRef]

19. Kim, T.W.; ValdéS, J.B.; Yoo, C. Nonparametric Approach for Estimating Return Periods of Droughts in Arid Regions. J. Hydrol. Eng. 2003, 8, 237-246. [CrossRef]

20. Salvadori, G. Bivariate return periods via 2-Copulas. Stat. Methodol. 2004, 1, 129-144. [CrossRef]

21. China Meteorological Data Sharing Service System. (1960-2014). Available online: http://cdc.cma.gov.cn (accessed on 30 October 2019).

22. Su, B.; Jiang, T.; Jin, W. Recent trends in observed temperature and precipitation extremes in the Yangtze River basin, China. Theor. Appl. Climatol. 2006, 83, 139-151. [CrossRef]

23. Klein Tank, A.; Ko “nnen, G. Trends in indices of daily temperature and precipitation extremes in Europe, 1946-1999. J. Clim. 2003, 16, 3665-3680. [CrossRef]

24. Vicente-Serrano, S.M.; Beguería-Portugués, S. Estimating extreme dry-spell risk in the middle Ebro valley (northeastern Spain): A comparative analysis of partial duration series with a general Pareto distribution and annual maxima series with a Gumbel distribution. Int. J. Climatol. 2003, 23, 1103-1118. [CrossRef]

25. Yevjevich, V. Objective Approach to Definitions and Investigations of Continental Hydrologic Droughts; Hydrology Paper 23; Colorado State University: Fort Collins, CO, USA, 1967.

26. Mckee, T.B.N.; Doeskin, N.J.; Kleist, J. Drought Monitoring with Multiple Time Scales. In Proceedings of the 9th Conference on Applied Climatology, Dallas, TX, USA, 15-20 January 1995; p. 505.

27. Sklar, A. Fonctions de Repartition an Dimensions et Leurs Marges; Publ. inst. statist University Paris: Paris, France, 1959; Volume 8, pp. 229-231.

28. Nelsen, R. An Introduction to Copulas, 2nd ed.; Springer: New York, NY, USA, 2006.

29. Joe, H. Dependence Modeling with Copulas. In CRC Monographs on Statistics \& Applied Probability; Chapman \& Hall: London, UK, 2014.

30. Durante, F.; Sempi, C. Principles of Copula Theory; CRC/Chapman \& Hall: Boca Raton, FL, USA, 2015.

31. Salvadori, G.; De Michele, C.; Kottegoda, N.; Rosso, R. Extremes in Nature. An approach using Copulas. In Vol. 56 of Water Science and Technology Library Series; Springer: Dordrecht, The Netherlands, 2007; ISBN 978-1-4020-4415-1.

32. Genest, C.; Favre, A. Everything you always wanted to know about copula modeling but were afraid to ask. J. Hydrol. Eng. 2007, 12, 347-368. [CrossRef]

33. Salvadori, G.; Tomasicchio, G.R.; D'Alessandro, F. Practical guidelines for multivariate analysis and design in coastal and off-shore engineering. Coast. Eng. 2014, 88, 1-14. [CrossRef]

34. Salvadori, G.; Durante, F.; Tomasicchio, G.R.; D'Alessandro, F. Practical guidelines for the multivariate assessment of the structural risk in coastal and off-shore engineering. Coast. Eng. 2015, 95, 77-83. [CrossRef]

35. Jiang, C.; Xiong, L.H.; Xu, C.Y.; Guo, S.L. Bivariate frequency analysis of nonstationary low-flow series based on the timevarying copula. Hydrol. Process. 2015, 29, 1521-1534. [CrossRef]

36. Willmott, C.J. On the validation of models. Phys. Geogr. 1981, 2, 184-194. [CrossRef]

37. Burnham, K.P.; Anderson, D.R. Model Selection and Multimodel Inference: A Practical Information-Theoretic Approach, 2nd ed.; Springer: New York, NY, USA, 2002.

38. Claeskens, G.; Hjort, N. Model Selection and Model Averaging, Cambridge Series in Statistical and Probabilistic Mathematics; Cambridge University Press: Cambridge, UK, 2008.

39. Mathier, L.; Perreault, L.; Bobée, B.; Ashkar, F. The use of geometric and gamma-related distributions for frequency analysis of water deficit. Stoch. Environ. Res. Risk Assess. 1992, 6, 239-254. [CrossRef]

40. Massey, F.J. The Kolmogorov-Smirnov Test for Goodness of Fit. J. Am. Stat. Assoc. 1951, 46, 68-78. [CrossRef]

41. Chen, L.; Singh, V.P.; Guo, S. Drought Analysis in the Upper Han River Based on multivariable method. In Proceedings of the AGU Fall Meeting, San Francisco, CA, USA, 5-9 December 2011.

42. Lee, T.; Modarres, R.; Ouarda, T.B.M.J. Data-based analysis of bivariate copula tail dependence for drought duration and severity. Hydrol. Process. 2013, 27, 1454-1463. [CrossRef] 
43. Salvadori, G.; De Michele, C. Frequency analysis via copulas: Theoretical aspects and applications to hydrological events. Water Resour. Res. 2004, 40. [CrossRef]

44. Salvadori, G.; Durante, F.; De Michele, C. Multivariate return period calculation via survival functions. Water Resour. Res. 2013, 49, 2308-2311. [CrossRef]

45. Salvadori, G.; De Michele, C.; Durante, F. On the return period and design in a multivariate framework. Hydrol. Earth Syst. Sci. 2011, 15, 3293-3305. [CrossRef]

46. Shiau, J.T. Return period of bivariate distributed extreme hydrological events. Stoch. Environ. Res. Risk Assess. 2003, 17, 42-57. [CrossRef]

47. Salvadori, G.; Michele, C.D.; Durante, F. Multivariate design via Copulas. Hydrol. Earth Syst. Sci. Discuss. 2011, 8, 5523-5558. [CrossRef]

48. Lotsch, A.; Friedl, M.A.; Anderson, B.T.; Tucker, C.J. Coupled vegetation-precipitation variability observed from satellite and climate records. Geophys. Res. Lett. 2003, 30, 107-218. [CrossRef]

49. Ransom, R.B.J. Biostatistical Analysis by J. H. Zar. Am. Biol. Teach. 1974, 36, 316. [CrossRef]

50. Gräler, B.; van den Berg, M.; Vandenberghe, S.; Petroselli, A.; Grimaldi, S.; De Baets, B.; Verhoest, N. Joint return periods in hydrology: A critical and practical review focusing on synthetic design hydrograph estimation. Hydrol. Earth Syst. Sci. 2013, 17, 1281-1296. [CrossRef]

51. Mirabbasi, R.; Fakheri-Fard, A.; Dinpashoh, Y. Bivariate drought frequency analysis using the copula method. Theor. Appl. Climatol. 2012, 108, 191-206. [CrossRef]

52. Zhang, D.D.; Yan, D.H.; Lu, F.; Wang, Y.C.; Feng, J. Copula-based risk assessment of drought in Yunnan province, China. Nat. Hazards 2015, 75, 2199-2220. [CrossRef]

(C) 2019 by the authors. Licensee MDPI, Basel, Switzerland. This article is an open access article distributed under the terms and conditions of the Creative Commons Attribution (CC BY) license (http://creativecommons.org/licenses/by/4.0/). 